\section{Teoria Política e o Funcionamento das Instituiçóes}

\section{Political Theory and the Functioning of Institutions}

WALDRON, Jeremy. Political Political Theory. Essays on institutions. Cambridge, MA: Harvard University Press, 2016. 416 p.

\section{Raphael Neves (1)}

E-mail: raphael.neves@unifesp.br

(1) Professor de direito constitucional da Unifesp, pesquisador do CEBRAP, SP, Brasil.

DOI: $10.1590 / 3610515 / 2020$

Se você é cientista político, certamente já teve de responder à pergunta fatal: "as instituiçóes estão funcionando?” O livro de Jeremy Waldron não é sobre o Brasil, mas pode ajudar a encontrar uma boa resposta. Professor de filosofia política e filosofia do direito na Universidade Nova York (NYU), Waldron é hoje um dos mais relevantes autores da tradiçáo liberal.

O livro tem doze capítulos, dos quais apenas três $(5,8$ e 11) são inéditos. Apesar de publicados anteriormente como artigos, eles formam uma unidade em torno do velho problema de como avaliar as instituições políticas. Ao propor uma teoria política politica, Waldron desenvolve uma "teoria política institucional" capaz de apresentar uma justificativa para arranjos institucionais. É exatamente isso que o livro tenta fazer, em certos momentos, de forma não tão exitosa.

Boa parte da discussão de Waldron leva em conta o contexto anglo-saxão. Isso ocorre não apenas por ele ser neozelandês e professor nos EUA, mas provavelmente porque o Reino Unido tem passado por grandes debates de reorganização institucional nos últimos tempos (o livro foi escrito antes do referendo da Brexit). Em primeiro lugar, a corte constitucional britânica foi instituída há pouco mais de uma década, em 2009. Nos últimos anos, aumentou o número de apoiadores de uma reforma para extinguir a Câmara dos Lordes e o bicameralismo. Some-se a isso a velha discussão sobre a separação de poderes, os limites do Executivo e o papel do constitucionalismo nas democracias contemporâneas.

O capítulo nove ("The Core of the Case against Judicial Review") é um conhecido texto de Waldron em que ele discute e critica o modelo de controle judicial de constitucionalidade (judicial review). Mais especificamente, o alvo de Waldron é o controle de constitucionalidade da legislação em um sentido forte, isto é, os casos em que "cortes têm autoridade para se recusar a aplicar uma lei em um caso específico ou modificar o efeito de uma lei para fazer com que sua aplicação esteja em conformidade com direitos individuais" (pp. 199-200). ${ }^{1}$

Quando a Suprema Corte dos EUA passou a ser presidida pelo conservador William Rehnquist, em 1986, muitos liberais, diz Waldron, passaram a se opor ao controle judicial de constitucionalidade. Um efeito parecido talvez ocorra agora, quando Trump tem a chance de fazer sua segunda nomeação para a Corte. Entretanto, o foco de Waldron não é fazer uma crítica com base no contexto histórico, nem sobre efeitos particulares. Sua crítica pretende ser teórica e normativa e diz respeito principalmente a dois aspectos. O primeiro é o de que o controle judicial "distrai" os cidadãos com questôes secundárias, como precedentes, textos e interpretação, deixando de lado o que realmente interessa: uma discordância em relação a direitos. O segundo ponto é o de que, ao privilegiar a escolha de alguns poucos juízes não eleitos, o controle judicial de constitucionalidade afasta a igualdade política dos cidadãos e os priva da resolução de questóes envolvendo direitos (p. 199).

Sem poder me aprofundar em detalhes do argumento, Waldron defende que um desacordo em relação a direitos permanece mesmo com a aprovação de uma Declaração de Direitos (Bill of Rights). Com o estabelecimento de um sistema de controle de constitucionalidade na sociedade, advogados de cada lado da discussão farão de tudo para argumentar que sua posição pode ser lida conforme o compromisso estabelecido na Carta. Segundo Waldron,

Ficará evidente que nenhum dos dois [lados] estará preparado para reconhecer o que estou assumindo agora: que a insípida retórica da Declaração de Direitos 
foi concebida em parte para suavizar os desacordos reais e razoáveis, inevitáveis entre as pessoas que levam os direitos a sério, por tempo suficiente para ver tal projeto de declaração promulgado. Em vez de nos encorajar a confrontar esses desacordos diretamente, é provável que o controle judicial as enquadre como questóes de interpretação daquelas formulaçôes insípidas. (p. 211)

Essa curta passagem talvez resuma bem o que seja mais problemático na tese defendida por Waldron: que desacordos morais precisam ser confrontados "diretamente" e que isso só ocorre - ou pelo menos é melhor confrontado - no Legislativo. A revisão das leis pelo Judiciário, ao contrário, reduziria aquele desacordo a uma mera "questão de interpretação".

Não fica claro o que Waldron quer dizer quando fala em "confrontar diretamente" os grandes dilemas envolvendo direitos. Ele apenas afirma que os juízes às vezes acabam se preocupando demais com os textos legais e fazem uma "discussão laboriosa dos precedentes" (p. 223), mas que "os precedentes não resolvem a questão”. Ele chega a dar como exemplo o fato de que, nas cinquenta páginas da decisão que prevaleceu em Roe v. Wade, apenas alguns parágrafos foram dedicados de fato a analisar a questáo moral envolvida. Esse é um argumento estranho. Em primeiro lugar, porque o debate legislativo também pode ser - e muitas vezes de fato é - permeado de barganhas e firulas retóricas.

Em segundo lugar, é curioso que Waldron, que faz questão de incluir um capítulo inteiro (cap. 12) no livro sobre "a política constitucional de Hannah Arendt”, desconsidere o papel, no exercício da autoridade, que Arendt (2011) atribui à Suprema Corte. É verdade que Arendt associava a autoridade à sua origem etimológica augere (aumentar e crescer), como lembra Waldron ao dizer que a Constituição é sempre um "trabalho em andamento" (p. 304). Entretanto, o que aumenta é a fundação - no caso da descrição arendtiana, a fundação de Roma. Há na noção de auctoritas uma ideia de ligação com o passado através do Senado romano, composto pelos descendentes dos fundadores da cidade já falecidos. É esse ato de se religar de volta ao início (ou religare, que Arendt atribui como sentido original da "religião" para os romanos) que configura o exercício da autoridade. Portanto, dessa perspectiva arendtiana, não deveria causar estranheza que boa parte do esforço dos juízes da Suprema Corte seja voltado aos precedentes, como forma de permanecer ligados a uma linha ininterrupta da qual emana sua autoridade.

Com isso, não quero dizer que o exercício de autoridade de uma corte constitucional deva necessariamente levar a uma interpretaçáo originalista da Constituição. Ela pode, ao contrário, tornar-se um "fórum de princípio", isto é, uma esfera privilegiada para a discussão dos desacordos morais envolvendo a aplicaçáo de direitos fundamentais. Mesmo nesse caso, a análise dos precedentes ainda preserva um papel importante. Para ficarmos no exemplo de Waldron, em Roe v. Wade a Suprema Corte constrói um argumento sobre o direito à privacidade que já vinha sendo reconhecido em decisóes anteriores ao caso do aborto. Os julgadores reforçam sua autoridade ao remeter esse direito à Constituição e aos juízes que os antecederam, e desenvolvem um argumento moral para resolver a controvérsia.

É claro que nada garante que a corte constitucional fará um bom trabalho. Até mesmo autores como Dworkin, que dedicou boa parte de seus textos a criticar as decisóes da Suprema Corte, reconhecem isso. Mas os juízes da corte constitucional não têm de se preocupar com sua reeleição e, mesmo decidindo casos concretos, sabem que suas razóes devem ser morais, pois afetam todos os cidadãos. Habermas (2020), por exemplo, busca dar uma fundamentação comunicativa para a separação entre Legislativo e Judiciário. ${ }^{2}$ Enquanto o parlamento está aberto à justificação das normas não só por meio de razóes morais, mas também ético-políticas, pragmáticas e até barganhas, os juízes da corte constitucional devem se valer de um tipo de discurso mais restrito, isto é, de aplicação e adequação das normas. Essas são diferenças importantes que elucidam porque o Judiciário acabou, funcional e historicamente, ficando a cargo daqueles desacordos.

Waldron deveria ter enfrentado melhor esse tipo de posicionamento a favor da revisão judicial a fim de fortalecer seu próprio argumento sobre a separação de poderes, no capítulo três. Nesse sentido, é bastante significativo um outro caso que aparece no livro. Ele cita a aprovação do Medical Termination of Pregnancy Act, 
de 1966, que legalizou o aborto na Inglaterra, como exemplo da capacidade do parlamento para enfrentar e resolver um desacordo sobre direitos. Em cada questão suscitada, diz ele, "uma ampla deliberação pública foi espelhada em um debate sério na Câmara dos Comuns". Além disso, "a qualidade desses debates torna absurda a afirmação de que os legisladores são incapazes de abordar tais questóes de forma responsável" (p. 196). O detalhe está no artigo sétimo, parágrafo terceiro, da lei de 1966 - não mencionado em momento algum por Waldron -, que diz: "[e]sta lei não se aplica à Irlanda do Norte”. Essa exclusão cria uma situação absurda do ponto de vista moral: às mulheres da Irlanda do Norte, onde o catolicismo é ainda muito forte, não se estende o direito ao aborto garantido para as demais mulheres do Reino Unido. Difícil imaginar como um argumento assim pode ser compatível com o liberalismo.

Outro ponto controverso é a leitura que ele faz de Montesquieu, pouco generosa, para dizer o mínimo. Ao mencionar o famoso capítulo VI do livro XI de O Espirito das Leis, ele cita este trecho:

Tampouco existe liberdade se o poder de julgar não for separado do poder legislativo e do executivo. Se estivesse unido ao poder legislativo, o poder sobre a vida e a liberdade dos cidadãos seria arbitrário, pois o juiz seria o legislador. (Montesquieu, 2005, p. 168)

Para em seguida tentar mostrar que Montesquieu não nos oferece "mais que tautologias". O argumento é parafraseado como "a falha de separar poderes leva à arbitrariedade porque envolve (...) uma falha em separar os poderes" (p. 60).

$\mathrm{Na}$ verdade, Montesquieu inicia esse capítulo tratando da "liberdade política". No trecho em questão, o ponto é que essa liberdade deixa de existir à medida que o poder é exercido de forma arbitrária. Quando o monarca ou o juiz acumulam, respectivamente, além do poder executivo e do poder de julgar, também o poder de legislar, há o temor de que eles se tornem arbitrários. E é essa arbitrariedade que elimina a liberdade política, uma vez que esta depende de que um cidadão não tenha motivos para temer outro cidadão. A suposta tautologia desaparece quando vemos que a falha de separar os poderes pode levar ao fim da liberdade política pois gera o temor de que a vida de cada um esteja sujeita ao arbítrio de quem acumula aqueles poderes. A ideia segundo a qual ser livre é não estar sujeito à arbitrariedade de outro nos remete, mais uma vez, a Arendt (2011) e sua conexáo com a tradição republicana.

Mas, se a formulação de Waldron a respeito da separação de poderes não é suficientemente liberal, nem tampouco republicana, qual sua especificidade? Ela parece basear-se em um argumento funcionalista. O ponto de Waldron é que a separação de poderes é pressuposta pela distinção vital entre várias funçôes de governo (legislativa, adjudicativa e executiva). A diferenciação ocorre não por uma necessidade de caráter normativo, mas devido à própria complexidade das ações de governo. Segundo Waldron, "é um erro pensar o exercício do poder político como algo simples" (p. 62). Assim, mesmo que os poderes fossem colocados todos nas mesmas mãos, seria preciso fazer a distinção dessas diferentes funções. A distinção de poder, diz ele, "nos é dada por uma teoria de governança articulada que enfatiza essas funçóes pelo que elas são, náo pelo que elas podem fazer para manterem umas sob o controle das outras" (p. 51).

Como esse "processo articulado" de governar se dá por meio do direito, Waldron consegue estabelecer um ponto de contato entre separação de poderes e rule of law. Insistir, segundo ele, em ser governado pelo direito é, dentre outras coisas,

insistir em ser governado por um processo que responde à articulação institucional exigida pela separação de poderes: deve haver legislação (lawmaking) antes de haver adjudicação ou administração, e deve haver adjudicação e o devido processo que ela implica antes de haver a execução (enforcement) de qualquer ordem. (p. 64-5)

Essa formulação permite, portanto, isolar a separação de poderes da questáo da legitimidade do exercício do poder político, como ele mesmo admite: "não importa se a autoridade em questão é em si mesma legítima, por exemplo, em função de suas credenciais democráticas" (p. 65). O que importa é que a complexidade exigida pela ação de governar seja canalizada através do direito e, assim, se torne 
funcionalmente diferenciada. Aqui, não parece estar em jogo a liberdade, a contenção do poder por outro poder (outra questão fundamental para Arendt) ou a legitimidade da própria adjudicação (como na teoria de Dworkin).

Sem dúvida, Waldron oferece uma abordagem com foco institucional, política em dobro, como o título do livro deixa claro. Mas, ao final da leitura, parece que isso se dá em detrimento da teoria. Nos dois últimos capítulos, ele pretende retomar a discussão teórica ao tratar de Isaiah Berlin e Hannah Arendt. Como tentei mostrar aqui, ao fazer sua análise das instituiçóes, ele parece não se engajar em uma discussão tão profunda com a teoria de Arendt. Por isso, no último capítulo, originalmente publicado em 2000, em um companion sobre a autora, Waldron não dá conta de amarrar teoricamente toda a discussão a respeito da separação de poderes, federalismo e constituição feita ao longo da obra. A discussão sobre Berlin (cap. 11) também desaponta.

Waldron denomina constitucionalismo do Iluminismo (Enlightenment constitutionalism) um pensamento surgido no século 18 , mas originado na Inglaterra no século anterior,

sobre formas de governo e a estruturação das instituiçóes de governo para promover o bem comum, assegurar a liberdade, limitar os monarcas, defender o governo da lei e tentar estabelecer o governo popular - representativo, se náo diretamente democrático - seguro e praticável para uma grande república moderna. (p. 275)

A essa "herança" ele conecta autores como Sieyès, Madison, Hamilton e Jefferson, Voltaire, Montesquieu, Rousseau, Lock, Kant, dentre outros.

A questão, então, passa a ser: por que Isaiah Berlin, um dos grandes intérpretes do pensamento iluminista, tem tão pouco a dizer sobre as realizaçóes dessa herança em termos de constitucionalismo e desenho institucional? O resgate teórico que Waldron faz desses autores e suas contribuições, principalmente na fundação constitucional dos EUA, é interessante, mas não impressiona. Por fim, o argumento baseia-se mais em uma especulação do que em uma interpretação dos textos de Berlin, que pouca coisa tem a acrescentar sobre o debate institucional, como Waldron mesmo reconhece.

Segundo ele, para Berlin, o "design social do iluminismo era arrogante e monista, buscando uma reconciliação tola de todos os valores e uma solução abrangente de todos os conflitos em uma brilhante obra da razão" (p. 283). O que Berlin parece não ter percebido é como, para os fundadores americanos, o desenho institucional era crucial para "abrigar", nos termos de Waldron, ao invés de reconciliar, o pluralismo de valores defendido pelo próprio Berlin.

Sem dúvida, há arranjos institucionais melhores ou piores para garantir, por exemplo, a liberdade negativa. Por isso, é louvável o esforço de Waldron em aprofundar a discussão institucional. Mas, ao fim, a impressão que temos é a de que as escolhas de arranjo que ele faz não estão suficientemente justificadas. Com efeito, há uma reivindicação normativa que não se encontra totalmente articulada. Além disso, como o livro também não pretende fazer uma análise mais abrangente de política comparada, ele toma o modelo anglo-saxão sempre como referência. Se a separação de poderes pode ser entendida como uma mera necessidade funcional diante da complexidade de governar, não seria o caso de examinar outros modelos mais centralizadores em que o governo é igualmente eficaz? Por que a separação de poderes seria, mesmo nesses casos, o desenho institucional preferido? Acho que mais - e não menos - teoria ajudaria a responder essa e outras perguntas que o livro nos traz.
Notas
1 Todas as citaçóes diretas foram traduzidas pelo autor da resenha.
2 Em especial no capítulo 6.

\section{Referências}

ARENDT, Hannah. (2011), Sobre a Revolução. Tradução: Denise Bottman. São Paulo: Companhia das Letras.

HABERMAS, Jürgen. (2020), Facticidade e Validade: contribuiçóes para uma teoria discursiva do direito e da democracia. Tradução: Felipe Gonçalves Silva e Rúrion Melo. Sáo Paulo: Editora Unesp.

MONTESQUIEU, Charles Louis de. (2005), O Espírito das Leis. $3^{a}$ ed. São Paulo: Martins Fontes. 